\title{
Solution Properties of Iron(III) Complexes with 5-Fluorosalicylic Acid - Spectra, Speciation, and Redox Stability
}

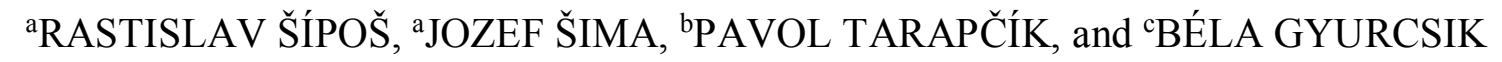

${ }^{a}$ Department of Inorganic Chemistry, Slovak Technical University, 81237 Bratislava, Slovakia

${ }^{b}$ Department of Analytical Chemistry, Slovak Technical University, 81237 Bratislava, Slovakia

${ }^{c}$ Department of Inorganic and Analytical Chemistry, Szeged University, Szeged, H-6720, Hungary

Corresponding author: Ing. Rastislav Š́́poš; sipos.rastislav@stuba.sk; Department of Inorganic Chemistry, FCHPT STU, Radlinského 9, 81237 Bratislava, Slovakia

Received

Dedicated to Professor Milan Melník on the occasion of his 70th birthday

Title running head: SOLUTION CHEMISTRY OF IRON(III) 5-FLUOROSALICYLATES

The iron(III)-5-fluorosalicylic acid systems were investigated in water by $\mathrm{pH}$ potentiometry combined with UV-VIS spectrophotometry. The data revealed that stable aquated mono-, bis-, and tris(5-fluorosalicylato) iron(III) complexes are formed, together with their monohydroxo and dihydroxo analogues. The stability constants of all present iron(III) species were calculated. Based on $\mathrm{pH}$ and metal:ligand ratio dependent distribution of the species, electronic absorption spectra of the complexes in the visible region were obtained. Redox stability was monitored as an ability to undergo both spontaneous and photoinduced reduction of Fe(III) to Fe(II). Complexes do not undergo any redox changes when in the dark both in methanol or water. While aqueous solutions of 
complexes are stable under the influence of incident visible radiation, steady-state irradiation of the methanolic systems by visible light led to the photoreduction of $\mathrm{Fe}(\mathrm{III})$ to $\mathrm{Fe}(\mathrm{II})$, the quantum yield of the $\mathrm{Fe}(\mathrm{II})$ photoformation was determined.

Keywords: Iron(III) complexes; 5-fluorosalicylic acid; spectra; speciation; photoredox chemistry;

\section{INTRODUCTION}

Data on iron(III) salicylates have found their utilization in industrial, biological, analytical and environmental areas. As an example of industrial application, heterometallic Ce(III)-Fe(III)salicylates acting as corrosion inhibitory layers on steel surfaces (Deacon et al., 2002) may be introduced.

Salicylic acid and its derivatives are commonly used radical scavengers, reacting rapidly with singlet oxygen molecules, hydroxyl $\mathrm{OH}^{*}$, superoxide $\mathrm{O}_{2}{ }^{\circ-}$ and hydroperoxyl $\mathrm{HO}_{2}{ }^{--}$radicals (Rose \& Waite, 2005; Ma, 2005, Karnik et al., 2007), frequently produced by iron(III) involving processes in living organisms or in the environment (Demouget et al., 2000; Zhang et al., 2006). In connection with studies devoted to Parkinson's disease treatment, the effect of iron(III) compounds on $\mathrm{OH}^{*}$ radical production has been investigated through salicylate hydroxylation (Obata, 2006). Similar procedure consisting in simultaneous application of iron(III) supressing the formation of free hydroxyl $\mathrm{OH}^{\bullet}$ radicals (in extracellular fluid of rat myocardium) and sodium salicylate scavenging the radicals is described in (Obata \& Yamanaka, 2002). It should be pointed out that the interaction of the present $\mathrm{Fe}(\mathrm{III})$ and salicylate anions has not been considered. Fe(III) can be reduced in its oxides and salicylates to $\mathrm{Fe}(\mathrm{II})$ by various bacteria under anaerobic conditions (Boneville et al., 2003). 
The importance of $\mathrm{Fe}(\mathrm{III})$ reduction by the superoxide radical $\mathrm{O}_{2}{ }^{--}$, formed by photochemical processes in seawater has been highlighted in (Rose \& Waite, 2005). Among the iron(III) complexes playing the role of a source of Fe(III), salicylates belong to the most reactive.

Salicylic acid is a frequently used reagent for analytical determination of Fe(III) (Martelli et al., 1995). A new dimension in analytical chemistry is documented in (Albertus et al., 2000), describing a robust multisyringe system in process flow analysis in metallurgical solutions. Another kind of application, flow-injection spectrophotometric assay of iron(III) using salicylate-containing reagent concerns analysis of pharmaceutical preparations (Udnan et al., 2004).

Iron(III) salicylato complexes are well-known species and their properties, in particular their thermodynamic stability and spectral properties have been exploited for long time. Our orientation on solution properties of iron(III) complexes with 5-fluorosalicylic acid has been stimulated by several factors.

First of them is well-known therapeutic activity of salicylic acid, its derivatives (e.g. aspirin) and complexes which has been observed and utilized for many decades (Palanisami et al., 2006; Szabó-Plánka et al., 2008). A general requirement to optimize the therapeutic agents composition to obtain a maximum cure and minimum adverse effects via lowering the amount of the agents, has led to the investigation of solution properties of several families of complexes, also including salicylates. In this field, several key questions have not been, however, still answered. As an example, in the up-to-now accumulated results, the existence of mixed ligand iron(III) hydroxo salicylato complexes has not been taken into account (Lajunen et al., 1997; Jahagirdar, 1974; Martell \& Smith, 1989) in spite of the known strong acidity of the $\left[\mathrm{Fe}\left(\mathrm{H}_{2} \mathrm{O}\right)_{6}\right]^{3+}$ cation. Apparently the only exemption forms paper (Ernst \& Menashi, 1963) where the presence of the hydroxo complex $[\mathrm{Fe}(\mathrm{OH}) \mathrm{L}]$ is suggested in the $\mathrm{pH}$ range $2-2.8$. The issue of soluble hydroxo complexes is of crucial importance when discussing the possibilities of in vivo application, i.e. at $\mathrm{pH}$ close to 7.

Further stimulus lies in the empirically recognized but theoretically not fully explained fact that within several structurally similar families of therapeutically functioning compounds, 
fluoroderivatives are frequently the most effective. This conclusion can be exemplified by quinolones that are used along with salicylates in the treatment of several diseases (Hooper \& Rubinstein, 2003).

In the present work, we report on the study of the iron(III) complexes of 5-fluorosalicylic acid in aqueous solution. Our studies were aimed at identifying the species formed in the investigated systems and characterizing the ligand coordination mode. Due to the importance of photochemical stability for practical application, the redox stability of the investigated systems were monitored both in the dark and in the presence of visible light.

\section{EXPERIMENTAL}

\section{Materials}

The ligand 5-fluorosalicylic acid (analytical grade) was purchased from Aldrich. It is symbolized by $\mathrm{H}_{2} \mathrm{~L}$ in its neutral form when giving the composition of various complexes. $\mathrm{Fe}\left(\mathrm{NO}_{3}\right)_{3} \cdot 9 \mathrm{H}_{2} \mathrm{O}$ (analytical grade) was purchased from Aldrich. Doubly deionized water and methanol freshly distilled from $\mathrm{Mg}\left(\mathrm{OCH}_{3}\right)_{2}$ were used as solvents. Other reagents were of analytical grade, supplied by Aldrich or Lachema and used as received.

The precise concentrations of $\mathrm{HClO}_{4}, \mathrm{NaOH}$ and $\mathrm{Fe}\left(\mathrm{NO}_{3}\right)_{3}$ in their stock solutions were determined by standard titration methods (Harvey, 2000).

\section{Combined pH-potentiometric and spectrophotometric titrations}

The protonation equilibria in aqueous solutions were investigated in the $\mathrm{pH}$ range $1-11$, while those in the presence of metal ions in the range $1-5.5$ since at higher $\mathrm{pH}$ precipitation of hydroxo-oxo iron(III) compounds occured. Four series of solutions with the molar ratio of $n\left(\mathrm{Fe}^{3+}\right)$ : $n\left(\mathrm{H}_{2} \mathrm{~L}\right)=1: 1 ; 1: 3 ; 1: 5$ or $1: 10$ and the corresponding total $c\left(\mathrm{Fe}^{3+}\right)=1.84 \times 10^{-3} \mathrm{~mol} \mathrm{dm}^{-3} ; 6.60 \mathrm{x}$ $10^{-4} \mathrm{~mol} \mathrm{dm}^{-3} ; 4.07 \times 10^{-4} \mathrm{~mol} \mathrm{dm}^{-3}$, and $2.06 \times 10^{-4} \mathrm{~mol} \mathrm{dm}^{-3}$, respectively, were subjected to potentiometric and spectrophotometric measurements. 
Details on the spectrophotometric measurements and $\mathrm{pH}$-potentiometric titrations are reported in our previous paper (Szabó-Plánka et al., 2008). The used glass electrode was calibrated via the modified Nernst equation (Rosotti \& Rosotti, 1962):

$$
E=E_{0}+K \cdot \log \left[\mathrm{H}_{3} \mathrm{O}^{+}\right]+J_{\mathrm{H}} \cdot\left[\mathrm{H}_{3} \mathrm{O}^{+}\right]+\frac{J_{\mathrm{OH}} \cdot K_{\mathrm{w}}}{\left[\mathrm{H}_{3} \mathrm{O}^{+}\right]}
$$

where $J_{\mathrm{H}}$ and $J_{\mathrm{OH}}$ are fitting parameters in acidic and alkaline media, respectively, for the correction of experimental errors caused mainly by the liquid junction, and the alkaline and acidic errors of the glass electrode; $K_{\mathrm{w}}=10^{-13.75}$ is the autoprotolysis constant of water (Högfeldt, 1982). The parameters were calculated by the non-linear least squares method. The protonation equilibrium of $\mathrm{H}_{2} \mathrm{~L}$ was studied under similar conditions also in 1:1 methanol:water mixture. The present experiments form part of a series, where not all the ligands and complexes are satisfactorily soluble in pure water. For comparison within the data we have performed measurements also in solvent mixtures.

The protonation constants were determined from 3 independent titrations (100-120 data points per titration). The complex formation constants were evaluated from 4 independent titrations (60-90 data points per titration). The corresponding protonation constants $K_{a}$ were calculated using the PSEQUAD computer program (Zékány et al., 1991).

A total number of absorbing complexes present in any solution at the given conditions was estimated applying the graphical method described in (Momoki et al., 1969) and also through determining the matrix rank using triangularisation of absorbance matrix (our own version of a TRIANG program (Hartley et al., 1980)). The distribution of the species in solutions was calculated using the PSEQUAD program.

The dependencies of absorptivity on $\mathrm{pH}$ were processed for all spectrophotometrical experiments with different metal:ligand ratio simultaneously at 47 wavelength by non-linear regression. The VIS electronic absorption spectra of individual iron(III) 5-fluorosalicylato complexes and their stability constants were obtained. 


\section{Dark and photochemical redox stability}

Solutions of investigated complexes in water or methanol are stable when being in the dark, no spectral change or Fe(II) formation were observed during several days. Aqueous or methanolic solutions with the total $c\left(\mathrm{Fe}^{\mathrm{III}}\right)=4.0 \times 10^{-4} \mathrm{~mol} \mathrm{dm}{ }^{-3}$ and $c\left(\mathrm{H}_{2} \mathrm{~L}\right)=1.2 \times 10^{-3} \mathrm{~mol} \mathrm{dm}^{-3}$ were irradiated with visible light $(350-600 \mathrm{~nm})$ in a three-compartment temperature-controlled (20 $\pm 1)^{\circ} \mathrm{C}$ ) quartz photoreactor (Applied Photophysics), radiation of the high-pressure $150 \mathrm{~W} \mathrm{Hg}$-lamp being filtered passing through a saturated aqueous solution of $\mathrm{CuSO}_{4}$. The irradiated solution was deoxygenated by purging with argon 30 minutes prior and during irradiation. The intensity of the incident monochromatized radiation was determined with ferrioxalate and Reinecke's salt actinometry performed before and after a series of photolytic experiments.

Radical formation was monitored by spin-trapping EPR technique using 5,5-dimethyl-1pyrroline- $N$-oxide (DMPO) and nitrosodurene (ND) as spin-traps. The course of the photoredox change was monitored by electronic absorption spectroscopy as time evolution of $c\left(\mathrm{Fe}^{\mathrm{II}}\right)$, details are described in our previous papers (Šima et al., 1999; Renz et al., 1995).

\section{RESULTS AND DISCUSSION}

To obtain information on the species present in solutions of kinetically labile complexes, three experimental techniques, namely potentiometric titration, UV-VIS absorption spectroscopy, and two-dimensional EPR spectroscopy are usually applied (Szabó-Plánka et al., 2008). In case of high-spin iron(III) complexes, the techniques used are reduced only to the two former ones. In addition, LF bands of spin-forbidden transitions of such complexes are of very low intensity (usually with the molar absorptivity $\varepsilon<1 \mathrm{~mol}^{-1} \mathrm{dm}^{3} \mathrm{~cm}^{-1}$ ), overlapped by more intense LMCT or IL bands (Šima \& Makáňová, 1997). Thus, contrary to, e.g. copper(II) or nickel(II) complexes, LF bands cannot be exploited to reveal any structural information. 
In this work, potentiometry and electronic absorption spectroscopy were applied to obtain the acidity constant of the ligand 5-fluorosalicylic acid $\left(\mathrm{H}_{2} \mathrm{~L}\right)$, stability constants of iron(III) species present in the investigated systems, speciation of the species in dependence on $\mathrm{pH}$ and the central atom:ligand molar ratio, and the electronic absorption spectra of individual iron(III) containing species.

Protonation and iron(III) complexation of 5-fluorosalicylic acid in aqueous solution as studied by the combined pH-potentiometric and spectrophotometric method

The protonation constant of the carboxylic group of unsubstituted salicylic acid is $2.82 \pm$ 0.28 at $298 \mathrm{~K}$ and $0.1 \mathrm{~mol} \mathrm{dm}^{-3}$ ionic strength (Lajunen et al., 1997). The $\mathrm{p} K_{\mathrm{a}}$ for the phenolic hydroxy group of 5-halogenosalicylic acids falls between 12 and 13, as a consequence of the strong intramolecular hydrogen bond (Mentasti et al., 1980; Gupta et al, 1981; Corigli et al., 1982), it is too high to be precisely determined by $\mathrm{pH}$-potentiometry. The proton loss of this group of the free ligand does not play any role below $\mathrm{pH}=11$, where our measurements were carried out. On the other hand, for most of complexes the coordination of $\mathrm{L}^{2-}$ is postulated based on the conception that also the phenol $\mathrm{OH}$ group is deprotonated due to the ligand coordination (examples, see in the authoritative work (Martell \& Smith, 1989)). As for Fe(III) salicylato complexes in solution, both types of coordination, i.e. as $\mathrm{L}^{2-}$ and $\mathrm{HL}^{-}$have been suggested in literature (Martell \& Smith, 1989; Poulias et al., 1986). The same ambiguity follows from the crystal and molecular structures of iron(III) complexes (moreover, only a few structures are published). For example, the molecular structure of catena-(heptakis $\left(\mu_{2}\right.$-salicylato- $\left.O, O^{\prime}, O^{\prime \prime}\right)$-tetrakis(2,2'-bipyridyl)-(salicylato)undecaaqua-tetra-iron(III)-dicerium(III)bis(2-hydroxybenzoate) ethanol solvate trihydrate documents that salicylato ligands are coordinated to the iron(III) central atom as $\mathrm{HL}^{-}$(via protonated phenolic $\mathrm{OH}$ group) (Deacon et al., 2002), but in diaqua-( $N, N$ '-bis(2-hydroxy-3- 
carboxybenzylidene)-1,2-diaminoethane- $O^{1}, O^{2}, O^{3}, O^{4}$ )-iron(III) chloride trihydrate, deprotonated phenolic oxygen atom is a donor atom (Zarembowitch et al., 1982).

Complying with the majority of descriptions of the salicylato ligand coordination, we accepted $\mathrm{L}^{2-}$ form in this paper. The $\mathrm{p} K_{\mathrm{a}}$ of the carboxylic group of 5-fluorosalicylic acid in aqueous solution, calculated from the ligand titration curves, is $2.60 \pm 0.01$, which is in good agreement with the value of 2.70 from the literature (Poulias et al., 1986). In $50 \%(\mathrm{v} / \mathrm{v})$ water/methanol mixture, this $\mathrm{p} K_{\mathrm{a}}$ is $3.06 \pm 0.01$ from $\mathrm{pH}-$ potentiometry. The value of $\mathrm{p} K$ follows a general trend (Lajunen et al., 1997) of a slight decrease due to the presence of halogen atom when compared with unsubstituted salicylic acid.

The limited solubility of the ligand in water allowed to carry out the $\mathrm{pH}$-potentiometric titrations at the ligand concentrations approaching to $c\left(\mathrm{H}_{2} \mathrm{~L}\right)=2 \times 10^{-3} \mathrm{~mol} \mathrm{dm}^{-3}$ as a maximum. Therefore, a careful planning of the titration experiments was necessary in order to be able to precisely follow the metal ion induced processes, to achieve a ligand excess but still cover as broad $\mathrm{pH}$ range as possible, and to have absorbance high enough for the combined potentiometric and spectrophotometric measurements. Under such circumstances, the maximum ligand:metal concentration ratio was 10:1. The $\mathrm{pH}$-potentiometric titration curves measured at $1: 1,1: 3,1: 5$ and 1:10 metal:ligand total concentration ratios, are depicted in Figure 1. (In all cases, some strong acid was added to the solution before titration in order to ensure acidic conditions at the beginning of the measurement.). Under the mentioned conditions, neither supersaturated solutions nor insoluble hydroxo-oxo iron(III) compounds are formed, these phenomena were observed only at $\mathrm{pH}>6$. 


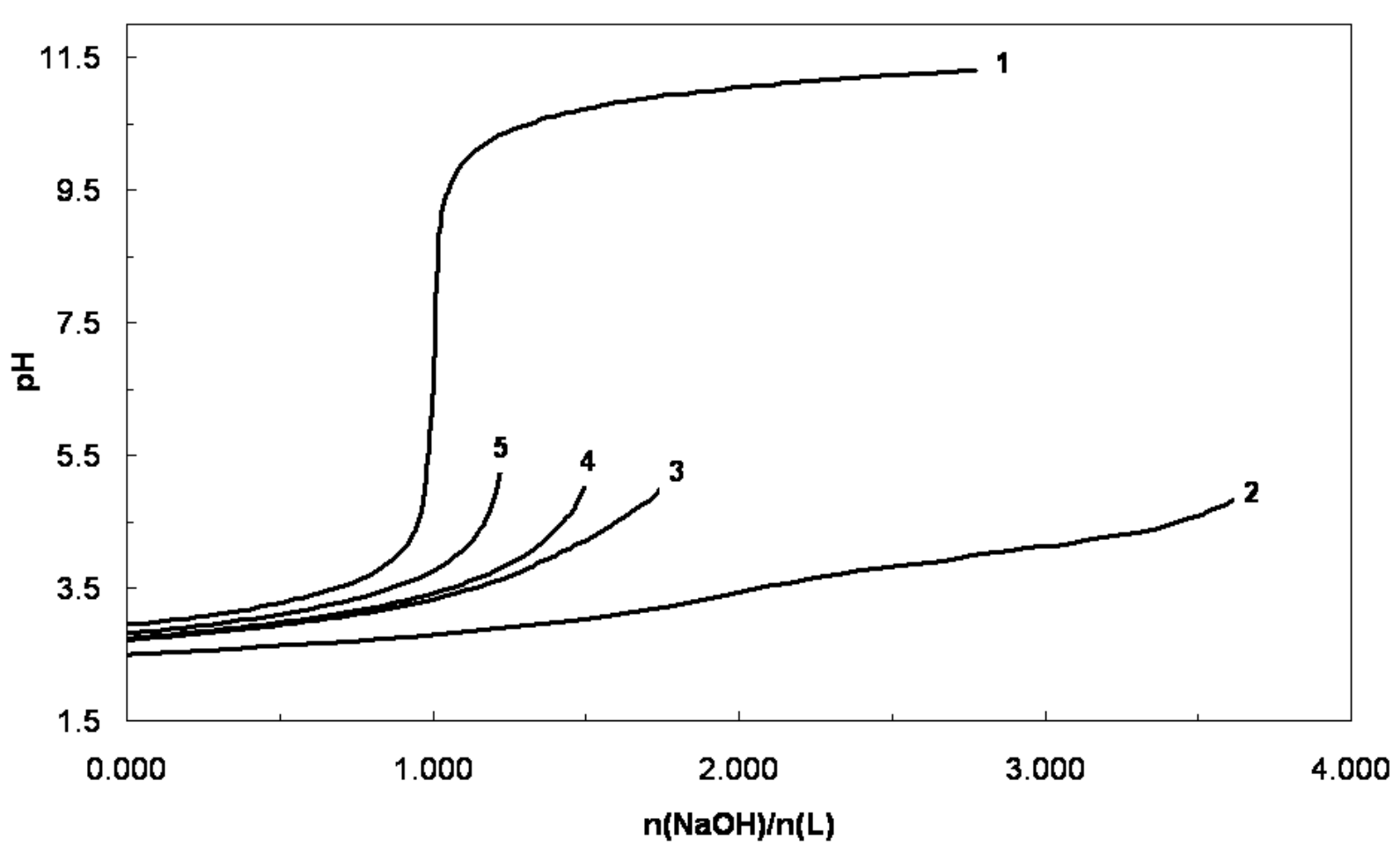

Fig. 1. The pH-potentiometric titration curves for 5-fluorosalicylic acid and for the iron(III)-5fluorosalicylic acid systems at different metal-to-ligand concentration ratios. $1-0: 1,2-1: 1,3-1: 3,4-1: 5$. $5-1: 10$.

Aquated $\mathrm{Fe}^{3+}$ ions undergo hydrolysis leading, at acidic conditions, to $[\mathrm{Fe}(\mathrm{OH})]^{2+}$. Shifting the $\mathrm{pH}$ to a higher value (still, however, $\mathrm{pH}<7$ ), even the formation of dihydroxo or oxo complexes, e.g. $\left[\mathrm{Fe}(\mathrm{OH})_{2}\right]^{+}$or $[\mathrm{Fe}(\mu-\mathrm{O}) \mathrm{Fe}]^{4+}$ are to be taken into account. It is believed that the latter complex could be omitted at lower $\mathrm{Fe}^{3+}$ concentrations. It is worth pointing out that all such species bear a positive charge. In this paper the following values of stability constants were adopted from literature sources: for the sake of completeness of the model, the stability constants of all possible monomeric hydroxo species $\log \beta_{1}\left([\mathrm{Fe}(\mathrm{OH})]^{2+}\right)=11.8 ; \log \beta_{2}\left(\left[\mathrm{Fe}(\mathrm{OH})_{2}\right]^{+}\right)=22.3$; $\log \beta_{3}\left(\left[\mathrm{Fe}(\mathrm{OH})_{3}\right]\right)=30 ; \log \beta_{4}\left(\left[\mathrm{Fe}(\mathrm{OH})_{4}\right]^{-}\right)=34.4$ (Kotrlý \& Šucha, 1988) were considered. The constants were recalculated for the ionic strength $I=0.1 \mathrm{~mol} \mathrm{dm}^{-3}$ according to the SIT procedure (Grenthe, 1992) and are as follows: $11.17 ; 21.23 ; 28.75 ; 33.1$ for $\log \beta_{1}, \log \beta_{2}, \log \beta_{3}$, and $\log \beta_{4}$, respectively. 
Electronic absorption spectra variation due to a gradual increase of the volume of added $\mathrm{NaOH}$ solution are exemplified by the systems with $c\left(\mathrm{Fe}^{3+}\right): c\left(\mathrm{H}_{2} \mathrm{~L}\right)=1: 1$ or $1: 3$ and shown in Figures 2 and 3, respectively.

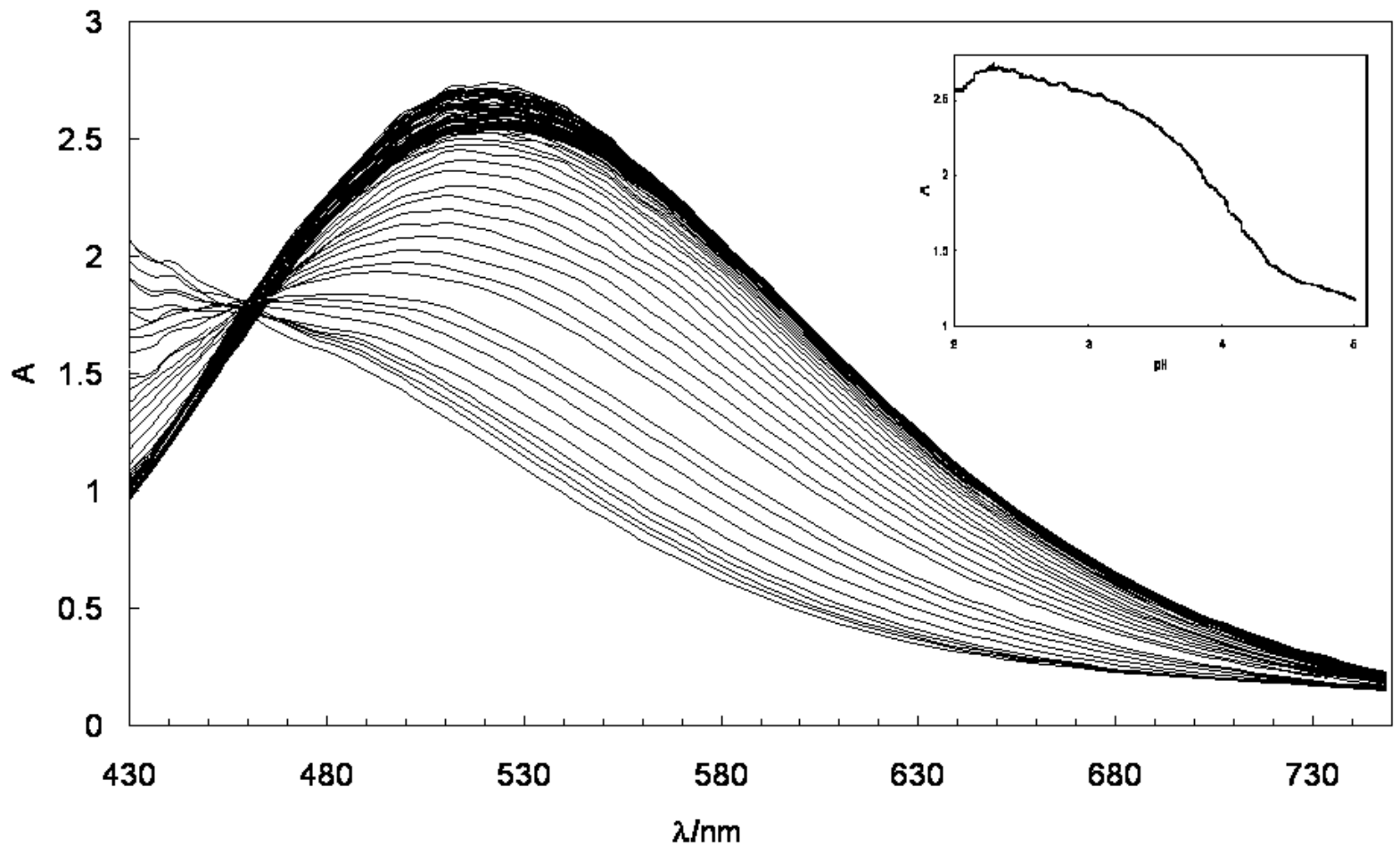

Fig. 2. Electronic absorption spectrum for the titrated system with $c\left(\mathrm{Fe}^{3+}\right): c\left(\mathrm{H}_{2} \mathrm{~L}\right)=1: 1$. The curve in the insert represents a $\mathrm{pH}$ dependence of the absorbance at $530 \mathrm{~nm}$.

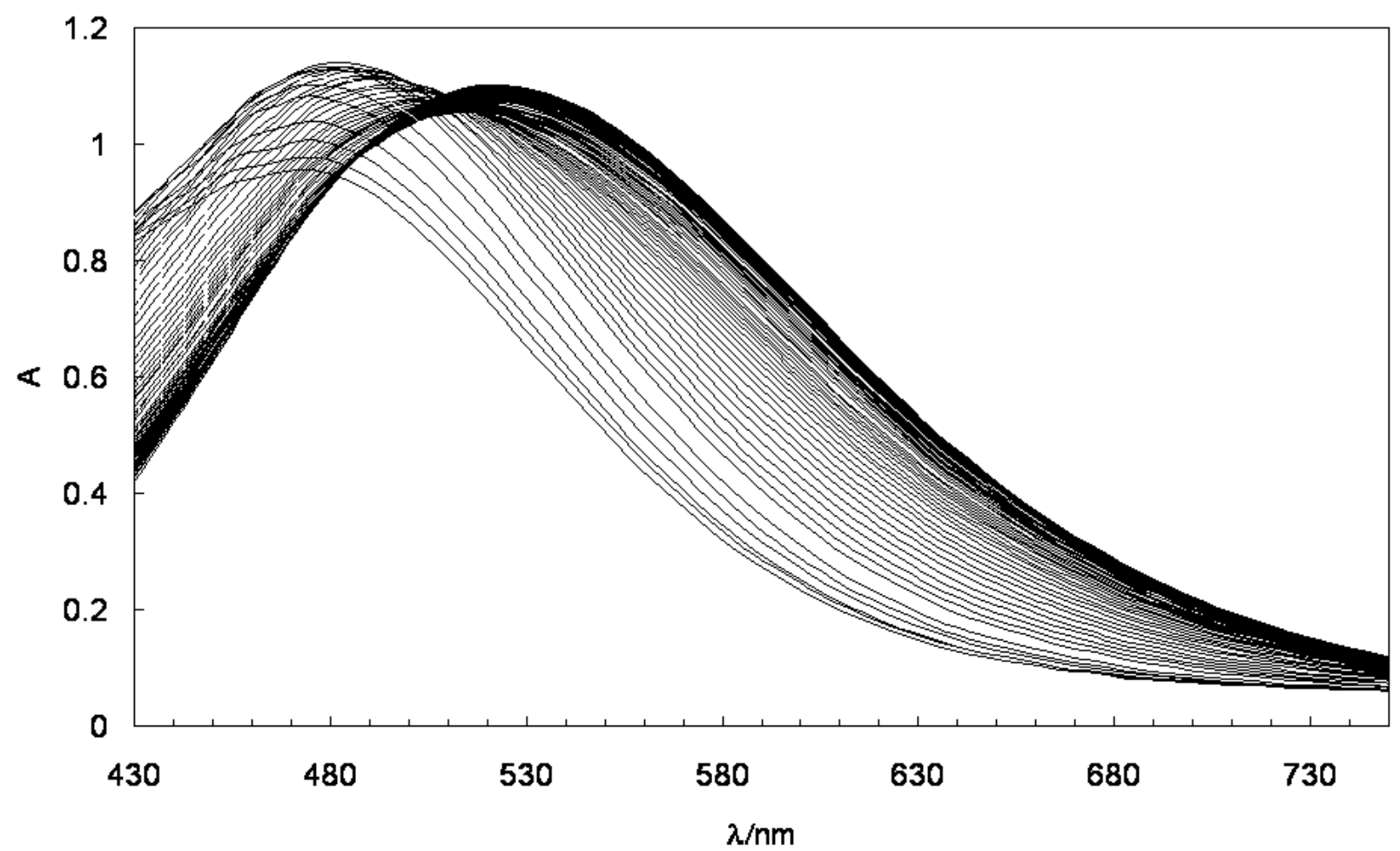

Fig. 3. Electronic absorption spectrum for the titrated system with $c\left(\mathrm{Fe}^{3+}\right): c\left(\mathrm{H}_{2} \mathrm{~L}\right)=1: 3$ 
It should be pointed out that there is no actual isosbestic point in Fig. 2. It is documented by the curve in the insert showing that the absorbance at $\lambda>530 \mathrm{~nm}$ first increases with $\mathrm{pH}$ increasing and later $(\mathrm{pH}>2.2)$ it slightly decreases. The absence of isosbetic points in Fig. 2 and Fig. 3 is in accordance with the fact that more than two light-absorbing complexes are in equilibrium.

Determination of a total number of absorbing species must be an essential part of such study. To reach this goal, several graphic and numeric procedures are at disposal. Graphic procedures are based on transformations of the measured curves to straight lines or a set of straight lines. Numeric procedures establish a range of the matrix used to describe the experiment by a set of equations. We performed the analysis of our data based on the procedures described in the literature (Beck \& Nagypal, 1989; Meloun \& Havel, 1985). This determination shows that there is no experimental condition range where the system of species can be considered as a simple system with less than three absorbing species and this conclusion was applied in the chemical model elaboration.

A subsequent simulation of the system of light-absorbing species was carried out simultaneously for all solutions and 24 wavelengths in the range $430-700 \mathrm{~nm}$. When elaborating models, the simplest system of species formation describing the experiment with sufficient precision was searched for.

When processing the experimental results, the coordinated ligand was considered as $\mathrm{L}^{2-}$ and both aqua and hydroxo complexes were taken into account. In parallel way, $\mathrm{HL}^{-}$was included in the calculation. Both methods provided almost identical compliance of the models and experiment (the dispersions of regresion curves were similar). This fact did not allow decide which of the models was more reliable and, in addition, it was not possible to distinguish acceptability of the treated models even based on potentiometric experiments. Moreover, one cannot a priori exclude coordination of salicylic acid both as $\mathrm{L}^{2-}$ and $\mathrm{HL}^{-}$. The description of complexes with coordinated $\mathrm{L}^{2-}$ is, however, more frequent and consistent with the majority of published results and we applied 
it as well. Models involving $\mathrm{HL}^{-}$may, in the future, complete conceptions on such systems, if new, more adequate experiments will be applied.

Treatment of the experimentally gathered data by the programs mentioned in the experimental section led to the stability constants of individual complexes, gathered in Table 1 .

Table 1

$\mathrm{pH}$-potentiometric formation constants as $\log \beta$ and absorption spectral data for the metal complexes detected in aqueous solutions in the iron(III) -5 -fluorosalicylic acid system. Uncertainties in $\log \beta$ values given by the program used are \pm 0.1 .

\begin{tabular}{lcc} 
Complex & $\log \beta$ & $\lambda_{\max } / \mathrm{nm}\left(\varepsilon_{\max } / \mathrm{mol}^{-1} \mathrm{dm}^{3} \mathrm{~cm}^{-1}\right)$ \\
\hline$[\mathrm{FeL}]^{+}$ & 17.4 & $522(1670)$ \\
\hline$\left[\mathrm{FeL}_{2}\right]^{-}$ & 33.1 & $499(1710)$ \\
\hline$\left[\mathrm{FeL}_{3}\right]^{3-}$ & 45.3 & $470(1960)$ \\
\hline$[\mathrm{FeL}(\mathrm{OH})]$ & 27.1 & $528(1630)$ \\
\hline$\left[\mathrm{FeL}(\mathrm{OH})_{2}\right]^{-}$ & 37.0 & $435(1440)$ \\
\hline$\left[\mathrm{FeL}_{2}(\mathrm{OH})^{2-}\right.$ & 42.8 & $453(2210)$ \\
\hline$\left[\mathrm{FeL}_{2}(\mathrm{OH})_{2}\right]^{3-}$ & 51.7 & $435(1170)$
\end{tabular}

The data for iron(III) complexes of salicylic acid in the literature in $0.1 \mathrm{M} \mathrm{NaClO}_{4}$ are as follows: $\log \beta\left([\mathrm{FeL}]^{+}\right)=16.3, \log \beta\left(\left[\mathrm{FeL}_{2}\right]^{-}\right) \sim 29$ and $\log \beta\left(\left[\mathrm{FeL}_{3}\right]^{3-}\right) \sim 41$ (Lajunen et al., 1997). Data for 5-Cl-substituted salicylic acid are as follows: $\log \beta\left([\mathrm{FeL}]^{+}\right)=15.5, \log \beta\left(\left[\mathrm{FeL}_{2}\right]^{-}\right) \sim 28$ and $\log \beta\left(\left[\mathrm{FeL}_{3}\right]^{3-}\right) \sim 39$ (Lajunen et al., 1997). Data for 5-Br-substituted salicylic acid are as follows: $\log \beta\left([\mathrm{FeL}]^{+}\right) \sim 15.5, \log \beta\left(\left[\mathrm{FeL}_{2}\right]^{-}\right) \sim 28$ and $\log \beta\left(\left[\mathrm{FeL}_{3}\right]^{3-}\right) \sim 39$ (Lajunen et al., 1997). Data for 5-I-substituted salicylic acid are as follows: $\log \beta\left([\mathrm{FeL}]^{+}\right) \sim 15.5, \log \beta\left(\left[\mathrm{FeL}_{2}\right]^{-}\right) \sim 27$ and $\log \beta\left(\left[\mathrm{FeL}_{3}\right]^{3-}\right) \sim 36$ (Lajunen et al., 1997).

In spite of the fact that the mixed-ligand hydroxo species were not considered in (Lajunen et al., 1997), our results are still in good agreement with the above data.

Simultaneously, the electronic absorption spectra of individual complexes were obtained. The spectra are shown in Figure 4. 


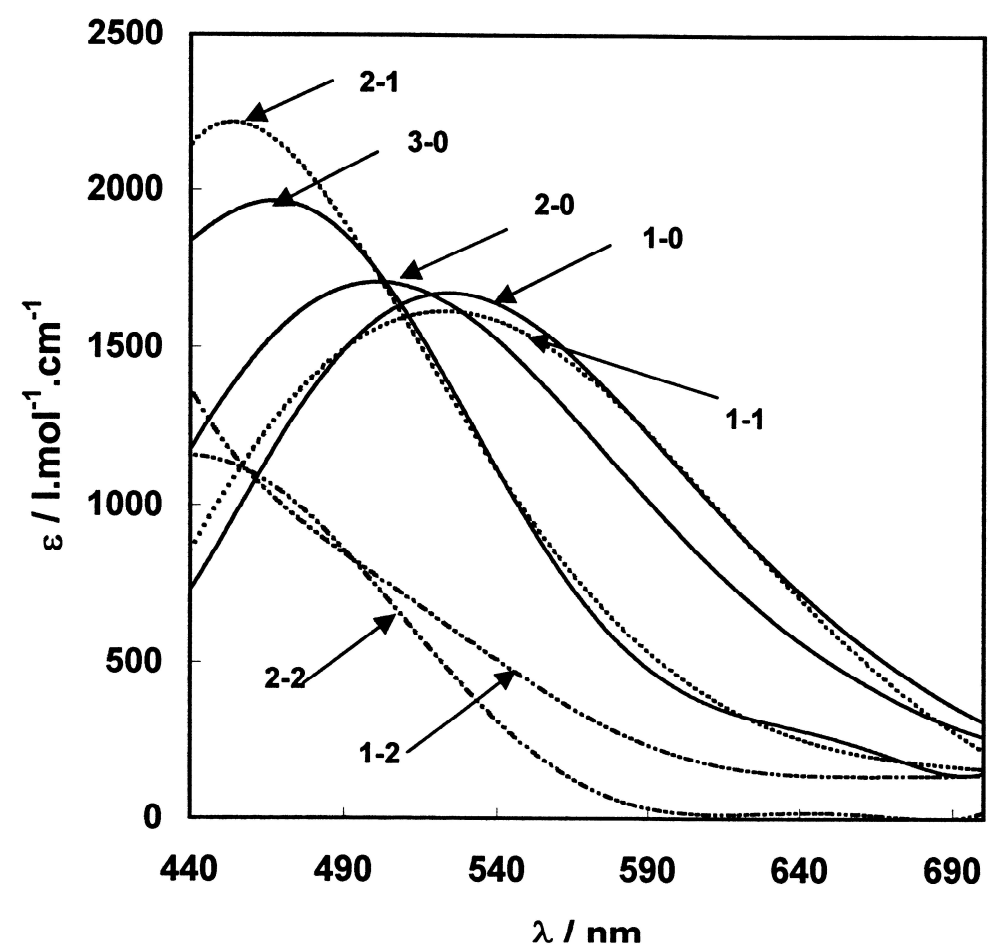

Fig. 4. Calculated spectra of complexes, $1-0=[\mathrm{FeL}]^{+}, 2-0=\left[\mathrm{FeL}_{2}\right]^{-}, 3-0=\left[\mathrm{FeL}_{3}\right]^{3-}, 1-1=[\mathrm{FeL}(\mathrm{OH})]$,

$$
1-2=\left[\mathrm{FeL}(\mathrm{OH})_{2}\right]^{-}, 2-1=\left[\mathrm{FeL}_{2}(\mathrm{OH})\right]^{2-}, 2-2=\left[\mathrm{FeL}_{2}(\mathrm{OH})_{2}\right]^{3-}
$$

It follows from the stability constants values (Table 1) that the coordination of 5fluorosalicylato ligand(s) enhances the tendency of coordinated water molecules to undergo hydrolysis leading to the mixed ligand hydroxo complex formation. A similar tendency was revealed and rationalized for other systems of iron(III) chelates too (Šima et al., 2006). The stoichiometries of the complexes can be determined from the consumed hydroxide ions by the released protons upon complex formation in a fairly straightforward manner. Since by $\mathrm{pH}-\mathrm{metry}$ it is not possible to distinguish between the protons released by the organic ligand, and the coordinated water molecules, spectrophotometry exploiting the fact that LMCT (phenolate- $\mathrm{O}^{-} \rightarrow$ $\mathrm{Fe}^{3+}$ ) bands are situated in the 400-600 $\mathrm{nm}$ range, was applied. Therefore the spectrophotometric data in the visible range provide a useful help in the constraction of the species matrix. Our data, and also the literature data on salicylic acid provide a clear proof for the deprotonation of the phenolic $\mathrm{OH}$ at very low $\mathrm{pH}$ values. 
Calculated values of the stability constants allow preparing solutions with targeted distribution of individual species with one dominant complex. As examples, Figs. 5 and 6 present distribution of individual 5-fluorosalicylato complexes (for the sake of simplicity, the species not containing 5-fluorosalicylato ligands are not included). It is obvious that there is a possiblity to prepare systems with the dominant concentration of the complex with one 5-fluorosalicylato ligand, $[\mathrm{FeL}]^{+}$(Fig. 5) and two such ligands, $\left[\mathrm{FeL}_{2}\right]^{-}$(Fig. 6). Since the ligand allows only very small concentration of uncomplexed iron(III), in such diluted solutions we considered the dimerization as negligible. To prepare a system with dominant neutral $\left[\mathrm{FeL}_{3}\right]^{3-}$ complex, the total concentration of 5-fluorosalicylic acid would has to be higher.

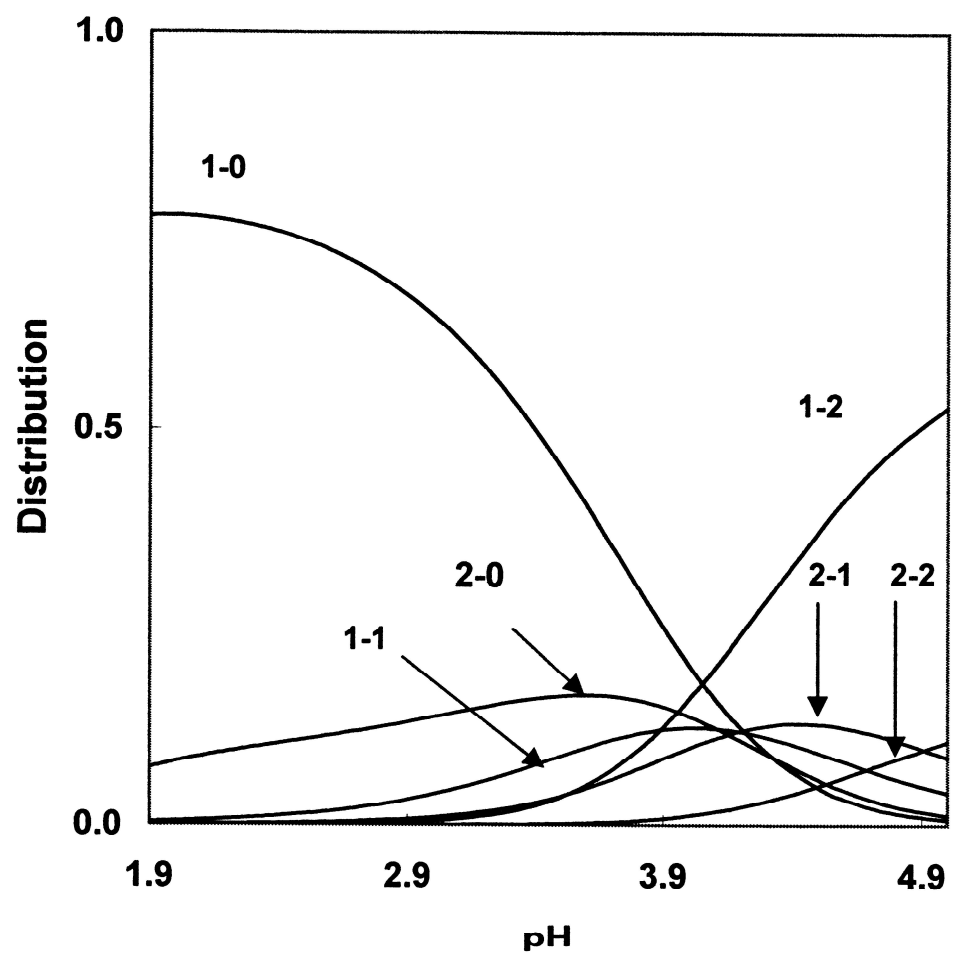

Fig. 5. The distribution of iron(III) amongst the various species, calculated by using the formation constants in Table 1, at 1:1 ligand to metal ratio, 1-0 - $[\mathrm{FeL}]^{+}, 2-0-\left[\mathrm{FeL}_{2}\right]^{-}, 1-1-[\mathrm{FeLOH}], 1-2-\left[\mathrm{FeL}(\mathrm{OH})_{2}\right]^{-}$, $2-1-\left[\mathrm{FeL}_{2}(\mathrm{OH})\right]^{2-}, 2-2-\left[\mathrm{FeL}_{2}(\mathrm{OH})_{2}\right]^{3-}$. In the investigated systems, $c\left(\mathrm{H}_{2} \mathrm{~L}\right)=1.8 \times 10^{-3} \mathrm{~mol} \mathrm{dm}^{-3}$ 


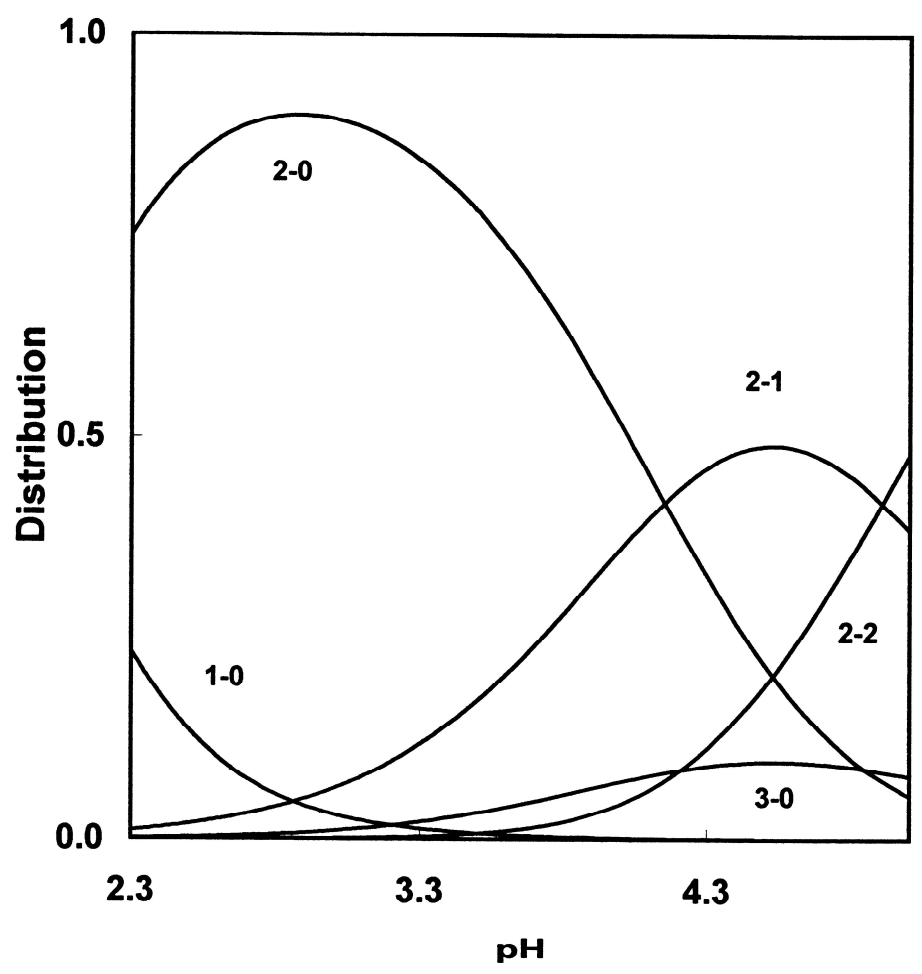

Fig. 6. The distribution of iron(III) amongst the various species, calculated by using the formation constants in Table 1, at 3:1 ligand to metal ratio, 1-0 - $[\mathrm{FeL}]^{+}, 2-0-\left[\mathrm{FeL}_{2}\right]^{-}, 3-0-\left[\mathrm{FeL}_{3}\right]^{3-}, 2-1-$ $\left[\mathrm{FeL}_{2}(\mathrm{OH})\right]^{2-}, 2-2-\left[\mathrm{FeL}_{2}(\mathrm{OH})_{2}\right]^{3-}, \mathrm{c}\left(\mathrm{H}_{2} \mathrm{~L}\right)=1.8 \times 10^{-3} \mathrm{~mol} \mathrm{dm}^{-3}$

Iron(III) 5-fluorosalicylato complexes in water or methanol are redox stable in the dark. Their irradiation by visible light in methanol causes photoreduction of $\mathrm{Fe}(\mathrm{III})$ to $\mathrm{Fe}(\mathrm{II})$ characterized by the quantum yield of the order $10^{-3}$. The aqueous solutions are photochemically stable. This observation is of practical importance as it documents that the investigated complexes can be handled at conditions of daily light (contrary to some other iron(III) chelates, e.g. oxalates, which are highly photosensitive and must be protected from light (Šima \& Makáňová, 1997)). Applying spin-trapping EPR using DMPO or ND spin-traps no radical was identified which is not suprising based on a well-documented ability of salicylato group to act as a very efficient scavenger of $\mathrm{OH}$ radicals (Obata, 2006).

The knowledge of electronic absorption spectra of individual complexes and its distribution enable to study photochemical properties of individual light-absorbing species, which is, however, beyond the scope of this paper. 
Acknowledgements. This work was performed in the framework of Slovak-Hungarian Intergovernmental S\&T Cooperation. Furthermore, the financial support of the Hungarian Scientific Research Fund OTKA (Grant T-469153) and the Slovak Academy of Sciences (Grants VEGA 1/2452/05 and APVT-20-005504) is gratefully acknowledged.

\section{REFERENCES}

Albertus, F., Cladera, A., and Cerda V. (2000). A robust multisyringe system for process flow analysis. Part II. A multi-commuted injection system applied to the photometric determination of free acidity and iron(III) in metallurgical solutions. Analysts, 125, $2364-$ 2371. DOI: 10.1039/b0042501.

Beck, M., Nagypal, I. (1989). Chemistry of Complex Equilibria. Budapest: Akademiai Kiado.

Bonneville, S., Behrends, T., Haese, R., and Van Cappellen, P. (2003), Thermodynamic constraints on microbial iron oxide reduction. In Geophysical Research Abstracts, 5, April 06-11, 2003 (12591). Nice: EGS-AGU-EUG Joint Assembly.

Corigli, R., Secco, F., and Venturini, M. (1982). Equilibriums and kinetics of complex formation at gallium(III). Evidence for an associative mode of activation, Inorganic Chemistry, 21, 29922998. DOI: $10.1021 / \mathrm{ic} 00138 \mathrm{a} 016$.

Deacon, G. B., Forsyth, C. M., Behrsing, T., Konstas, K., and Forsyth, M. (2002). Heterometallic $\mathrm{Ce}^{\mathrm{III}}-\mathrm{Fe}^{\mathrm{III}}-$ salicylate networks: models for corrosion mitigation of steel surfaces by the 'Green' inhibitor, Ce(salicylate) $)_{3}$. Chemical Communication, 2820-2821. DOI: 10.1039/b207722a. 
Demougeot, C., Marie, C., and Beley, A. (2000). Importance of iron location in iron-induced hydroxyl radical production by brain slices. Life Science, 67, 399-410.

Ernst, Z.L., Menashi, J. (1963). Complex formation between the $\mathrm{Fe}^{3+}$ ion and some substituted phenols. Part 1. - Spectrophotometric determination of the stability constant of ferric salicylate. Transactions of the Faraday Society, 59, 1794-1802. DOI: 10.1039/TF9635901794.

Grenthe, I. (1992). Chemical Thermodynamics of Uranium. Amsterdam: NEA, North-Holland.

Gupta, V., Shtapak, J., and Sharma, D. (1981). Stability constants for copper complexes of substituted salicylic acids, Journal of Inorganic and Nuclear Chemistry, 43(11), 3019-3022.

Hartley, F.R., Burgess, C., and Alcock, R.M. (1980). Solution Equilibria. New York: Ellis Horwood.

Harvey, D. (2000). Modern Analytical Chemistry, pp. 278-350. New York: McGraw-Hill.

Hooper, D. C. and Rubinstein, E. (2003). Quinolone Antimicrobial Agents, 3rd. ed. Washington: ASM Press.

Högfeldt, E. (1982). in: Stability Constants of Metal-Ion Complexes, Part A. Inorganic Ligands, p. 32, New York: Pergamon.

Jahagirdar, D. V. (1974). Potentiometric studies of Fe(III) complexes of some substitued salicylic acids. Journal of Nuclear and Inorganic Chemistry, 36, 2388-2390.

Karnik B. S., Davies S. H., Baumann M. J., Masten S.J. (2007). Use of Salicylic Acid as a Model Compound to Investigate Hydroxyl Radical Reaction in an Ozonation-Membrane Filtration Hybrid Process. Environmental Engineering Science, 24(6), 852-860. DOI:

10.1089/ees.2006.0156.

Kotrlý, S., and Šucha, L. (1988). Chemical Equilibria in Analytical Chemistry. Praha: SNTL

Lajunen L. H. J., Portanova, R., Piispanen J., and Tolazzi, M. (1997). Stability constants for alphahydroxycarboxylic acid complexes with protons and metal ions and the accompanying 
enthalpy changes - Part I: Aromatic ortho-hydroxycarboxylic acids. Pure \& Applied Chemistry, 69, 329-381.

Ma, J-H. (2005). Reactions of Hydroxyl Radical with Salicylic Acid Derivatives: A Pulse Radiolysis Study. Chinese Journal of Chemistry, 23, 1273-1274. DOI: 10.1002/cjoc. 200591273 .

Martell, A. E. and Smith, R. M. (1989). Critical Stability Constants, 4th ed. New York: Plenum Press.

Martelli, P. G., Reis, B. F., Kronka, E. A. M., Bergamin, H., Korn, M., Zagatto, E. A. E., Lima, J. L. F. C., and Araujo, A. N. (1995). Multicommutation in flow analysis. Part 2. Binary sampling for spectrophotometric determination of nickel, iron and chromium in steel alloys. Analytica Chimica Acta, 308, 397-405.

Meloun, M., Havel, J. (1985). Computation of Solution Equilibria, 1. Spectrophotometry. Brno: J. E. Purkyně University Press.

Mentasti, E., Secco, F., and Venturini, M. (1980). Complex formation between nickel(II) and cobalt(II) with salicylic acids. Equilibriums and reaction mechanisms, Inorganic Chemistry, 19, 3528-3531. DOI: 10.1021/ic50213a064.

Momoki K., Sekino J., Sato H., and Yamaguchi N. (1969). Theory of curved molar ratio plots and a new linear plotting method. Analytical Chemistry, 41, 1286-1299. DOI: 10.1021/ac60279a008.

Obata, T. (2006). Effect of desferrioxamine, a strong iron (III) chelator, on 1-methyl-4phenylpyridinium ion $\left(\mathrm{MPP}^{\wedge}+\right)$-induced hydroxyl radical generation in the rat striatum. European Journal of Pharmacology, 539, 34. DOI: 10.1016/j.ejphar.2006.03.071.

Obata, T. and Yamanaka, Y. (2002). Iron (III) attenuates hydroxyl radical generation accompanying non-enzymatic oxidation of noradrenaline in the rat heart. Naunyn Schmiedebergs Archives of Pharmacology, 365, 158-163. 
Palanisami, N., Prabusankar, G., and Murugavel, R. (2006). A novel dimeric copper salicylate with an undissociated $\mathrm{COOH}$ group: Synthesis and crystal structure of $\left[\mathrm{Cu}_{2}(\mathrm{HSal})(\mathrm{Sal})\left(2,2^{\prime}-\right.\right.$ bpy) $\left.{ }_{2}\right]\left(\mathrm{ClO}_{4}\right)$. Inorganic Chemistry Communications, 9, 1002-1006. DOI: 10.1016/j.inoche.2006.05.025.

Poulias, G., Papadopoulos, N., and Jannakoudakis, D. (1986). Dissociation of 5-fluoro- and 3,5dinitrosalicylic acids in water-methanol mixtures at $25^{\circ}$, Talanta, 33, 461-462.

Renz, F., Linert, W., Fleischauer, P., Klement, R., Mazúr, M., Šima, J., and Boča, R. (1995). Iron(II) Spin Crossover System: [Fe(bzimpy) 2$]\left(\mathrm{ClO}_{4}\right)_{2}$. In Current Trends in Coordination Chemistry, June 5-9, 1995 (p. 303-308), Bratislava: STU Press.

Rose, A. L. and Waite, T. D. (2005). Reduction of Organically Complexed Ferric Iron by Superoxide in a Simulated Natural Water. Environmental Science and Technology, 39, 2645-2650. DOI: 10.1021/es048765k.

Rosotti, F. J. C. and Rosotti,H. (1962). in: The Determination of Stability Constants, pp. 149-150, New York: McGraw-Hill.

Szabó-Plánka, T., Gyurcsik, B., Nagy, N. V., Rockenbauer A., Šípoš, R., Šima, J., and Melník, M. (2008). Complexation of 5-fluorosalicylic acid with copper(II): A pH-potentiometric, UVvis spectroscopic, and electron spin resonance study by the two-dimensional simulation of spectra, Journal of Inorganic Biochemistry, 102, 101-109. doi:

10.1016/j.jinorgbio.2007.07.019.

Šima, J. and Makáňová, J. (1997). Photochemistry of iron(III) complexes, Coordination Chemistry Reviews, 160, 161-189.

Šima, J., Mrázová, J., and Kotočová, A. (1999). Photoredox Properties of Iron(III) Fluoro Complexes Containing Tetradentate Open-Chain $\mathrm{N}_{2} \mathrm{O}_{2}$-Ligands. Journal of the Chinese Chemical Society, 46(6), 993-997. 
Šima, J., Šípoš, R., Izakovič, M., Valigura, D., and Tarapčík, P. (2006). Speciation and Spectra of Bromokojatoiron(III) Complexes in Aqueous Solutions. Polish Journal of Chemistry, 80, 1991-1999.

Udnan, Y., Jakmunee, J., Jayasavati, S., Christian, G. D., Synovec, R. E., and Grudpan, K. (2004). Cost-effective flow injection spectrophotometric assay of iron content in pharmaceutical preparations using salicylate reagent. Talanta, 64, 1237-1240. DOI: 10.1016/j.talanta.2004.03.067.

Zarembowitch, J., Kahn, O., Jaud, J., Galy, J. (1982). Versatility of iron(III) upon coordination with the binucleating ligand N,N'-bis-(2-hydroxy, 3-carboxybenzilidene)1,2-diaminoethane. Inorganica Chimica Acta, 65, L35-L36.

Zékány, L., Nagypál, I., and Peintler, G. (1991). PSEQUAD for Chemical Equilibria [computer sotware]. Baltimore, MD: Technical Software Distributors.

Zhang, C., Wang, L., Wu, F., and Deng, N. (2006). Quantitation of Hydroxyl Radicals from Photolysis of Fe(III)-Citrate Complexes in Aerobic Water. Environmental Science and Pollution Research - International, 13, 156 DOI: 10.1065/espr2005.10.287. 